\title{
Convenience matters: A qualitative study on the impact of use of social media and collaboration technologies on learning experience and performance in higher education
}

\author{
Yeona Jang \\ Desautels Business School, McGill University, Montreal, H3A 1G5, Quebec, Canada \\ E-mail: yeona.jang@mcgill.ca
}

\begin{abstract}
Social media and collaboration technologies are viewed as valuable tools for creating a new reality of collaborative learning, particularly in higher education facing millennials growing up with various technologies in their daily lives. Using the example of an undergraduate course taught on-campus, this study examines how millennial students in higher education use social media and other collaboration technologies in their collaborative learning activities to co-create new knowledge through the application of existing knowledge and the sharing of ideas. A semi-structured survey-based qualitative research method is used to reveal the primary decision factors driving students' technology choice for use in their collaborative learning tasks and to assess the impact of the use of such technologies on their learning experience and performance.

The analysis reveals convenience as an important decision factor impacting millennial students' choice of social media and collaborative technologies to use in their team-based collaborative learning interactions. In particular, the three salient types of convenience emerge that matter to millennial students: convenient to everybody in the team, convenient to access and use, and convenient to collaborate with each other privately within the team. The analysis suggests that the use of social media and collaboration technologies chosen by students in their collaborative learning activities is more likely to result in students with positive collaborative learning experience than otherwise. In addition, a moderately strong correlation $(r=0.425, p<0.01)$ is found between students' learning performance and their perception on the impact of the use of the technologies of their choice on learning experience. Based on the analysis, this study proposes a student-engaged, technology-choice-and-impact framework that captures the relationship between millennial students' convenience-driven technology choice and its impact on collative learning experience and performance. Further efforts should focus on investigating pedagogic designs that engage students in technology choice for improved collaborative learning experience and performance. The results of this study can inform educators and education technology providers in tailoring their approaches to incorporating technologies with learners in mind, thus turning their engagement into improved learning experience and performance.
\end{abstract}

Keywords: Knowledge sharing and collaboration, social media, collaboration technology, social affordance, collaborative learning, learning experience and performance, higher education

\section{Introduction}

\subsection{Context}

Fast commoditization in Information and Communication Technologies (ICTs) offers an increasing range of opportunities to incorporate these technologies into teach-

0167-8329/14/15/\$35.00 (C) 2014/2015 - IOS Press and the authors. All rights reserved

This article is published online with Open Access and distributed under the terms of the Creative Commons Attribution Non-Commercial License. 
ing and learning activities in higher education contexts [66]. Higher education has arguably entered a period of disruption, with potentially transformative change by new technological capabilities allowing new ways of teaching and learning [14|68]. In particular, social media are viewed as enabling tools for creating a new reality in education encouraging more active and proactive approaches to learning [10[37|40|51]. In contrast to personal computing which focuses on supporting a behavior of isolated individual users, social media is a term used to broadly define a variety of Internetbased social computing technologies with the emphasis on the social affordances for communication, collaboration, and content co-creation and remixing [29]. Many scholars noted the social affordances of social media to connect learners with one another, which can allow them to interact and learn from each other in a participatory and collaborative fashion. Combined with the pervasiveness of Internet and mobile computing devices on college campuses, social media offers a potential to create new instructional strategies for improved student engagement and collaborative learning in higher education [53].

The use of digital technologies in classroom settings is still, however, primarily relying on traditional learning management systems (LMS) without resulting in the innovative educational improvement which might have been expected [17]. The literature review by Tess [64] on the role of social media in higher education concludes that empirical evidence has lagged in supporting the claim of social media as tools for bringing innovative ways of teaching and learning in classrooms. It is also noted that the integration of traditional LMS and social media lacks connection between formal and informal environments to improve learning processes for the final users, in other words, learners [13]. In addition, the gap in attitudes towards technologies is observed between students and faculty in higher education. Roblyer et al. [52] found that in higher education, students are more positive about the potential of using Facebook and other new social computing technologies for supporting learning than faculty who prefer traditional technologies.

\subsection{Objectives}

The field of social media and mobile computing devices in higher education contexts can be summarized as still new and evolving. The existing literature indicates that most of the approaches to harnessing the technological resources in higher education have been mainly teacher-manipulated, arguably better suited for generations of students who tended to acquire knowledge more passively from authority figures. However, demographics entering the higher education space are changing. Millennials, born in the 1990's, are the demographic cohort growing up with various digital technologies in their daily lives, thus also known as tech-savvy digital natives. Independence, autonomy, and social interactions in their learning styles appear to be typical characteristics of how millennials tend to learn. Yet, little research has been done in understanding how millennials decide which digital technologies to use in 
their learning activities for collaborative knowledge generation and learning experience.

This study attempts to reveal dominant patterns of interactions displayed among students in team-based collaborative learning activities and their relationship with the students' technology choice and collaborative learning experience. Guided by the research question of "Does the use of knowledge sharing and collaboration technologies in collaborative learning activities improve students' collaborative learning experience and performance?" the objectives of this research are twofold: (1) to identify principal factors that impact students' decision on which technology tools to use in their team-based collaborative learning activities ("technology choice") and (2) to assess the impact of their technology choice on their collaborative learning experience and performance ("technology impact").

In particular, an on-campus course was designed in such a way that collaboration among students is required in their learning activities to apply theoretic concepts and frameworks to a real-world situation and problem solve together, i.e., co-creation of new knowledge through the application of existing knowledge and the sharing of ideas. A semi-structured survey-based qualitative approach is used for data collection and analysis. Millennial students are familiar with various social media and collaboration technologies with the same or similar social affordances. The study identifies the key principal factor that impacts students' technology choice, from a pool of such technologies, for use in their collaborative learning activities - convenience. The analysis of the resulting survey responses provides an informed basis for proposing a student-engaged, technology-choice-and-impact framework that conceptualizes the relationship between millennial students' technology choice and its impact on collative learning experience and performance.

\section{Literature review}

The push to innovate teaching and learning with the integration of Information and Communication Technologies (ICTs) has been a clear theme in higher education over the past decade. To understand the ways in which learning management systems, social media, and various other forms of ICTs were approached for higher education, two relevant streams of literature were reviewed: (1) literature on learning management systems and social media in higher education; and (2) literature examining the attitude of teachers and learners toward the incorporation of ICTs in educational programs.

\subsection{Incorporation of learning management systems and social media in higher education programs}

A learning management system (LMS) is the most popular education technology implemented in many higher education institutions with the goal of enhancing students' learning and developing teachers' professional capability. The focus of learning management systems in academic institutional environments has been mainly 
on course delivery, providing teachers with tools to support the traditional concept of classrooms and facilitate administrative tasks [6]35]. While learning management systems are primarily teacher-centric, these systems also attempt to provide students with virtual spaces in which they may perform their academic activities.

Another technology considered as valuable tools offering a transformative potential in education is social media, allowing users to create a new reality in education encouraging more active and pro-active approaches to learning [10]37|40|51]. Even though the term social media is often interchangeably used with Web 2.0, the literature differentiates it from Web 2.0 which is typically defined by technical design patterns [47]. Social media is defined more as "a group of Internet based applications that build on the ideological and technological foundations of Web 2.0, and that allow the creation and exchange of user generated content" [29, p. 61]. In contrast to personal computing which focuses on supporting a behavior of isolated individual users, social media is broadly defined as a variety of Internet-based social computing technologies that emphasize the social affordances of the Internet. Recognizing the social affordances of social media, many scholars argue for the integration of social media as effective educational tools [22[59]. McLoughlin and Lee [39] identified the following categories of social affordances associated with social media - connectivity and social rapport, collaborative information discovery and sharing, content creation, and knowledge and information aggregation and content modification. These social affordances suggest that social media can facilitate student engagement and collaborative learning that is defined, at the broadest, as "a situation in which two or more people learn or attempt to learn something together" [19]. Collaborative learning involves not only individuals as group members but also social interactions among them such as negotiation and sharing of meanings. In collaborative learning, learning occurs as they are actively sharing experience and ideas, asking one another, and evaluating information together in the process of meaning sharing and knowledge construction in a participatory and collaborative manner. Eijkman [20] observes how social media could move education away from a knowledge-object orientation of "what to know" toward process-driven, participatory knowledge construction approaches of "how to know." As the use of mobile technology grows in college campuses, ways to purposively leverage social media and mobile computing devices in structured formal learning are being investigated [43[55].

Various evaluation studies on the use of these technologies in higher education show, however, that empirical evidence has lagged in supporting the promise of digital technologies in higher education. Despite the fact that the majority of developed countries incorporated learning management systems in their education systems, the results are not what they had hoped for [17]. The use of a learning management system is often limited to publication and consumption of course content in a broadcasting mode where teachers publish content and students passively consume what is published [30[35[56]. A key criticism of LMS includes that these systems are mainly teacher-centric, being developed without learners in mind for their engagement, thus making their adoption and use a difficult task [15]. 
A literature review on the use of social media in higher education also indicates that empirical evidence has lagged in supporting the promise of social media [64]. Factors investigated in the use of social media in the higher education context include student engagement [23|26|62] and impact on student academic achievement [27|28]. The study by Junco et al. [28] showed that encouraging the use of Twitter can improve undergraduate students' engagement and semester grade point averages (GPA). However, the other study [27] observed a significantly negative relationship between the time spent on Facebook and undergraduate students' GPA. The increased ubiquity of social media, coupled with fast growing mobile computing devices on college campuses, offers the potential to explore new instructional strategies [25]. However, the field is still new and evolving with the extant literature being limited to the evaluation of the effectiveness of implementing these technology devices [55].

The various studies indicate that simply implementing learning management systems, social media, mobile computing devices, and other new similar technologies in educational programs do not automatically lead to transformational change in education with any meaningful improvement in learning outcomes for students. A criticism on learning management systems remains that these systems do not easily support the integration of new technological trends such as social media and new mobile app technologies to increase student participation and learning outcomes [2]. From the perspectives of student learning, Chen and Bryer [13] observes that traditional learning management systems are not integrated with social media in such a way that students' formal and informal learning environments are connected to improve these final users' learning processes. Formal learning is described as learning that is institutionally sponsored or highly structured with materials developed by a teacher within a program of instruction in an educational environment for a certificate or a credit, whereas informal learning as unstructured learning that happens often through observation, conversing with others, or using the Internet [36]. Oliver [46] argues that the further research should be explored to develop a deeper understanding of the relationship between technologies and learning in a pedagogical design of learning activities.

\subsection{Teachers' attitude toward the integration of digital technologies and changes in learners}

Incorporation of technologies into teaching and learning is affected to a large extent by what expectations teachers have regarding the use of these resources [18]42, 69]. Frameworks such as Technological Pedagogical and Content Knowledge [44 67] and decision models [78] were proposed to better equip teachers in designing, implementing, and evaluating curriculum and instructions with technology. Yet, educational uses of technologies by teachers for classroom teaching and learning are sporadic. Studies were conducted to measure teacher attitudes toward the integration of ICT into their daily teaching activities [11]65]. Roblyer et al. [52] found that in higher 
education, students are more positive about the potential of using Facebook and other new social computing technologies for supporting learning than faculty who prefer traditional technologies. Tess [64] concluded in his review of social media in higher education that teachers are slow in adopting social media for educational purposes.

Sasseville [58] made the observation that "Teachers believe that they can control recent changes in education with knowledge accumulated over the years from their professional experiences. They perceive professional knowledge as a way to steer technological change in a direction they can understand and which they feel is beneficial to their students." However, the validity of this teacher-driven approach to incorporating digital technologies in higher education should be challenged particularly with the change in demographic cohorts to tech-savvy millennials whose characteristics include a significant increase in familiarity with, and use of, social media and other digital technologies in their everyday lives [50,63]. In addition, independence, autonomy, and social interactions in their learning styles appear to be typical characteristics of how millennials tend to learn, unlike previous generations of students who typically acquired knowledge more passively from authority figures [32]. Demographic change, coupled with fast change in technologies, calls for the in-depth investigation of pedagogic strategies for student manipulation of technology to achieve student engagement and educational goals [1 $31|32| 58]$.

\subsection{This paper}

We can conclude from the literature review that while learning management systems, social media, and mobile computing devices offer potentials to innovate teaching and learning, the results of teacher-driven approaches to integrating these technologies into educational programs are far from the realization of the full potentials of these technologies in higher education. Digital-native, millennial students tend toward independence, autonomy, and social interactions with instant gratification, impacting their learning styles. Little research has been done, however, to understand what drives students' technology choice for use in their learning activities and how the use of the technologies chosen by them impacts their learning experience and performance. This paper aims to complement the existing literature by examining ways in which students decide to use these technologies in team-based collaborative learning activities and by proposing a student-engaged, technology-choiceand-impact framework that captures the relationship between students' technology choice and its impact on their collaborative learning experience and performance.

\section{Course design and method}

Digital-native millennial students are familiar with, and use, various social media and other digital technologies in their daily lives. What drives them to choose 
a certain technology tool over other competing familiar tools, for use in their collaborative learning activities? And, how would students' technology choice impact their learning experience and performance? Using the example of an undergraduate course taught in on-campus higher education, this study attempts to explain how millennial students in higher education choose and use social media and collaboration technologies in their team-based collaborative learning activities. The first part of this section provides the description of the course developed for undergraduate students in their final year. The development of the course was informed principally by the educational principles of constructivism. The second section of this section describes the qualitative research approach used in this study to explain students' technology choice for collaborative learning activities and its impact on their collaborative learning experience and performance.

\subsection{Course design}

A course, offered within the area of Information Systems at the Faculty of Management in McGill University, was redesigned to incorporate collaborative learning into the on-campus course delivery in 2013. The unit under discussion is a semesterlong elective course that, as described in its syllabus statement, allows students to "examine how Information Technology (IT) is leveraged in various industries. The course will draw from economic theories as well as from various IT management concepts to help create a framework. We will then examine specific real-world case studies to which we can apply these frameworks. Students will gain in-depth knowledge and skills in analysing how IT can drive various types of innovation to create value. Critical thinking, creative thinking, analytical skills, business writing and presentation skills, collaboration and team skills will all be part of the learning outcomes as these relate to IT in business." The course is studied by a mix of final-year students majoring different business management disciplines - information systems, marketing, finance, accounting, and general management. Thus, the course has a diverse cohort of students with different motives and expectations.

The key learning outcomes of the course consist of the two components - one is "hard" domain knowledge relevant to information technology management and the other "soft" skills that relate to IT in business and contemporary workplaces [4]. The main domain knowledge covers IT management concepts and the economic theories that help create the frameworks to systematically examine how organizations and industries can innovate to create business value from IT and to learn about how IT can both drive and hinder innovations. The soft skills include critical thinking, creative thinking, analytical skills, business writing and presentation skills, and collaboration skills, as illustrated in Fig. 1. To help students to develop the complex skills of critical thinking, creative thinking, and analytical skills, explicit expectations are set to the students with the behavioral guidance. More specifically, critical thinking behaviors assessed in this course include evaluating how far information is appropriate and relevant, determining how to interpret it, questioning evidence and assumptions, 


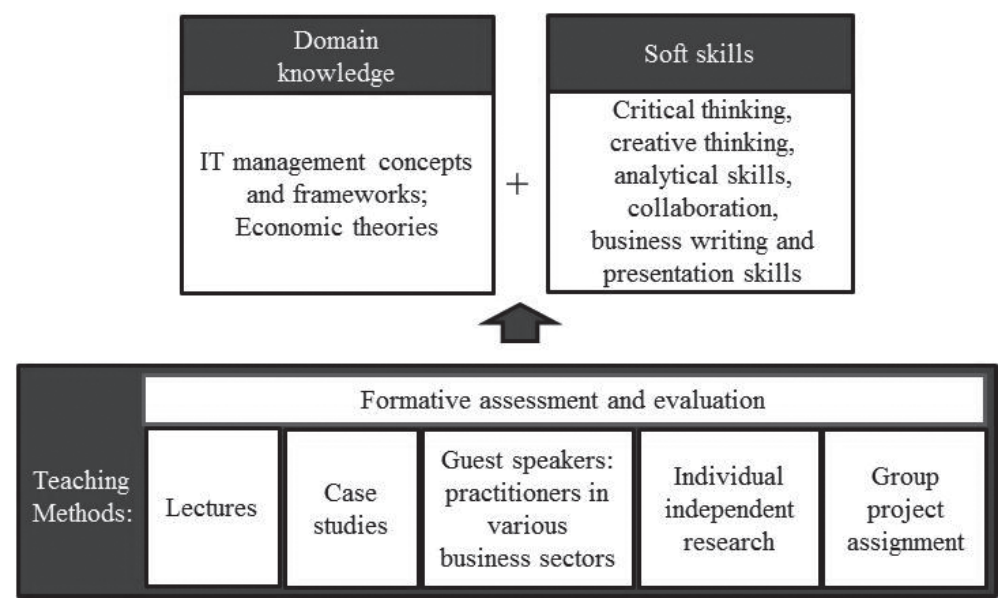

Fig. 1. Learning outcomes and teaching methods used.

checking whether evidence and arguments support the recommendations, and taking outside information into account during the thought process to explore other elements that could be of influence. The behavioral guidance provided to the students for creative thinking includes putting facts, concepts and conclusions together in new and original ways, looking for multiple alternatives to a problem, and learning from what has not worked (failures) as well as what did (successes). Analytical skills that are assessed in this course include systems thinking [60], problem identification, and problem analyzing and solving. Another soft skill component is collaboration. Roschelle and Teasley [54] defined collaboration as follows:

"Collaboration is a process by which individuals negotiate and share meanings relevant to the problem-solving task at hand ... Collaboration is a coordinated, synchronous activity that is the result of a continued attempt to construct and maintain a shared conception of a problem."

Collaboration involves working together, in which parties are not necessarily bound contractually or hierarchically. As a result, effective collaboration requires self-regulation of behavior to coordinate with others, with joint attention to maintain shared focus. Various studies show the benefits of collaboration in workplaces [34]38|4961]. Collaboration is also considered as an essential twenty-firstcentury skill [1641].

In designing the course, a formative approach was used for both assessment and evaluation. Much has been written about assessment and evaluation - two concepts that are complementary and necessary in education. Assessment is the term used to look at how learning is going and provide feedback on knowledge, skills, and work products for the purpose of improving the level of quality of a performance or outcome [48], while evaluation is the term used to describe the determination of the 
level of quality [5]. The summative approach, taken at the conclusion of an educational process, is often used in evaluation. However, both assessment and evaluation can be summative or formative, i.e., undertaken while an educational process is ongoing. A formative assessment and evaluation approach is used in this course to keep track of how students are learning throughout the semester.

The question that was faced in designing teaching methods was how to incorporate collaborative learning in such a way that the soft skills can be developed and used in connection with the learning of the domain knowledge, to achieve both of the learning outcomes. Influenced by the educational principles of constructivism, the multi-dimensional teaching method is designed in which lectures are complemented by various opportunities for students, individually and in teams, to apply the concepts and the theories taught in class to real-world situations. Honebein [24] defines social constructivist learning contexts as places "where learners may work together and support each other as they use a variety of tools and information resources in their guided pursuit of learning goals and problem-solving activities." A key premise of social-constructivist pedagogy is that instead of knowledge being transmitted by teachers to be passively acquired by learners, learners participate in constructing the means by which they create new knowledge and integrate it with existing knowledge [3|24].

Thus, a 10-week team project assignment is designed as a part of the course's teaching methods. The execution of the team project assignment requires collaboration with each other, as students perform learning activities together outside the classroom. This team project not only involves students as team members but also involves interactions among them to solve real-world problems together. The objective of this team project is to apply the knowledge that students acquire through the lectures, in-class case analyses and discussions, guest lectures by industry practitioners, and individual independent research, to 1) critically analyze how the structure of an industry has transformed over time and how IT has been a part of this transformation, 2) to identify the IT challenges that companies within an industry are facing, and 3) to make substantiated and implementable recommendations to address the IT challenges. The two key project deliverables that each team is required to complete are a written report summarizing their findings and recommendations and three in-class presentations of their work. Teams are formed during the second week of the semester. Students' team activity starts with the selection of an industry and a company in the industry to investigate. The first presentation occurs during the third week after the team formation. Each team shares, with other students in class, the industry and the company that they choose to investigate and the plan describing how they plan to execute the project as a team. Students in other teams can ask questions and provide feedback to the presenting team. The second team presentation occurs in class during the mid-term period to share their research effort to gather and analyze the data on the industry and the company that they are investigating. Other students in class can ask questions and provide feedback to the presenting team. Students conclude their 10-week-long team project activities by making the final, third 
team presentation in class. As each team shares their findings and recommendations, students in other teams again can ask questions, challenge the team's analysis and recommendations, and provide feedback on what they have learned from the presentation.

Effective planning and execution of this team project requires collaboration - in other words, students self-regulating their behavior to coordinate with their team members, with joint attention to maintain shared focus. The performance of the team project is evaluated at a team level, not at an individual level. A team's in-class presentations are evaluated based on content quality and coherence, coordination between speakers, question responsiveness, and the ability to stay within time frame, as well as speaking skills (poise, clear articulation, proper volume and pace, good posture, eye contact, enthusiasm, and confidence). A team's written report is evaluated for comprehension, clarity, conciseness, critical thinking, creative thinking, relevance of the IT management concepts and economic theories applied to their analysis and synthesis, and coherence of the report.

The university's LMS (hereafter, referred to as my courses) was used in this course throughout the semester. This LMS provides the discussion forum feature which is an online message board where students can post, and respond to, messages. Upon the completion of the team formation, a discussion forum dedicated to each team was created in my courses. Students were informed of the availability of these LMS discussion forums for use as their virtual team interaction sites. Students were empowered to pick and choose any type of digital technologies to use, including the LMS discussion forums, in their team collaboration - with the project objectives, evaluation criteria, and deadlines in mind. There was no teacher's intervention to mandate any particular technologies to use in their team collaboration.

\subsection{Methodology}

Since this research attempts to explain how millennial students in higher education choose and use social media and collaboration technologies in their team-based collaborative learning activities and reveal a relationship between the students' technology choice and learning experience and performance, a qualitative-method approach was deemed appropriate.

A semi-structured survey was developed to collect data on the technology tools that students used to do their team assignment together with their team members and on how the use of the technologies impacted their collaborative learning experience. The initial list of technology tools that students were familiar with were collected from the students at the beginning of the course. The initial list consisted of Facebook, Dropbox, Google Drive, Google Doc, Google Presentation, Google Spreadsheet, wikis, Twitter, Skype, email, and texting. The discussion forum in mycourses was added to this initial list to construct the final list of technologies for use in the semi-structured survey. All of these tools offer, at differing degrees, the social affordances identified by McLoughlin and Lee [39] - connectivity and social rapport, collaborative information discovery and sharing, content creation, and knowledge and 
Table 1

Study cohort: Team size and within-team diversity

\begin{tabular}{|c|c|c|c|c|c|}
\hline & Average & $\begin{array}{r}\text { Standard } \\
\text { deviation }\end{array}$ & Median & Minimum & Maximum \\
\hline Team size & 4.1 & 0.4 & 4.0 & 4.0 & 5.0 \\
\hline $\begin{array}{l}\text { Within-team diversity: } \% \text { of female } \\
\text { students in a team (Gender diversity) }\end{array}$ & $56 \%$ & $24 \%$ & $50 \%$ & $20 \%$ & $100 \%$ \\
\hline $\begin{array}{l}\text { Within-team diversity: The number } \\
\text { of business management disciplines } \\
\text { in a team }\end{array}$ & 2.3 & 0.9 & 2.0 & 1.0 & 4.0 \\
\hline
\end{tabular}

information aggregation and content modification. In the semi-structured survey, the following questions were asked for each technology tool in the list:

- Did you use it in doing your team project together with your team members?

- If used, why did you and your team choose this tool? Where and how did you and your team members use this tool for what purposes?

- If used, would you say that this tool helped you to have positive meaningful learning experience? If so, how did it help? If not, why not?

- If not used, why did your team not use this tool?

If students used any technology tool that was not on the list, they were asked to specify. A student was also asked to evaluate to the overall impact of the use of the technology tools on overall collaborative learning experience. For this, the following summary question was asked:

- Overall, would you say that the technology tools that you and your team members used to do this team assignment helped you to interact better with your team members and learn from each other, thus helping you to have positive, meaningful learning experience?

The survey was conducted at the end of the semester. Total 58 students, with the composition of 26 male students and 32 female students, took this on-campus course for credit. The course had a diverse cohort of students majoring different business management disciplines - information systems, marketing, finance, accounting, and general management, as summarized in Table 1.

The survey participation was on a voluntary basis at an individual level. The response rate was $88 \%$ ( 51 out of 58). The analysis of the data collected began after the team project grading was completed, in order to ensure the complete independence of team assignment grading from survey responses. Following the data collection process and after the completion of the team project grading, the survey data was analyzed in two stages. Both of the research interests (technology choice and technology impact) shaped our interpretations of the semi-structure survey responses that we collected and the explanations that we advance in this paper. We first performed an analysis to allow for common patterns to emerge, in order to explain students' primary decision factors in choosing certain technology tools for use in their collaborative learning activities. For the coding and analysis of survey responses, we followed 
Table 2

Tools chosen by students for use in their team-based collaborative learning activities

\begin{tabular}{lccc}
\hline & Used extensively & Used but not so much & Not used at all \\
\hline Facebook & $100 \%$ & - & - \\
Dropbox & $3 \%$ & $15 \%$ & $82 \%$ \\
Google Drive & $51 \%$ & $22 \%$ & $27 \%$ \\
Google Doc & $78 \%$ & $15 \%$ & $7 \%$ \\
Google Presentation & $51 \%$ & - & $49 \%$ \\
Wikis & - & $2 \%$ & $98 \%$ \\
Twitter & - & - & $100 \%$ \\
Skype & & $28 \%$ & $72 \%$ \\
Google Hangout & $14 \%$ & $14 \%$ & $86 \%$ \\
Emails & $14 \%$ & $86 \%$ & - \\
Texting & - & $86 \%$ & - \\
Discussion forum in mycourses & & - & $100 \%$ \\
\hline
\end{tabular}

a grounded theory approach for data analysis and conceptual development [12|21]. We then proceeded to a team-level analysis, applying the statistical analysis, to reveal the relationship between students' technology choice and its impact on collaborative learning experience and performance

\section{Findings}

\subsection{Technology choice drivers: Why do students choose certain technology tools over other competing familiar tools, to use in their team-based collaborative learning activities?}

Millennial students are using various social media, mobile computing devices, and other digital technologies in their daily lives. Our finding shows that even without the instructor's intervention, these students autonomously and collectively chose particular technology tools to use in their team collaboration, as summarized in Table 2.

To gain insights on what drives students to choose certain technology tools for use in their team collaboration, we analyzed the survey responses to "If used, why did you and your team choose this tool?" and "If not used, why did your team not use this tool?" The theme that emerged is convenience, i.e., a quality of being easy, useful, or suitable to proceed with something without difficulty (Oxford Dictionary). In particular, the analysis identifies the three salient types of convenience that appear to play a critical role in impacting students' technology choice for use in their team collaboration: convenient to everybody in the team, convenient to access and use, and convenient to collaborate with each other privately within the team.

\subsubsection{Convenient to everybody in the team}

The analysis of the responses reveals that students pick a certain technology tool, mainly because their team members are already using it: 
"Everyone in my team has a Facebook account. It is convenient to all."

"It's convenient because everyone already knows how to use it."

"We all have a Facebook account. It's easy to create a private group and communicate without leaving anyone out in the team. We check Facebook all the time."

"Facebook is a social network that all of our team members use, whether it's for class or personal. It is checked more often than emails, and easier/faster to respond to than emails."

"Everyone is on Facebook - when we're doing group projects, we want to get a response within a reasonable amount of time; we know our peers will be on Facebook so they're more likely to see it and respond in less time."

"We all have access to the Google Doc. It's convenient. We can work on the same document simultaneously, and it is easy to see the progress of other team members as well as what they are doing."

"I never used Google Doc before, but some of my team members did. They told me it is easy to work on documents simultaneously with no version control problem. So I said yes to it. I had a frustrating experience before in another project because one of the team members emailed me wrong versions all the time."

Wiki was not used much because not everybody in the team was familiar with it.

"I tried to use wiki in document collaboration, but not everybody in the team was familiar with it. So we didn't use it."

"We all are more familiar with Google Doc and have used it before. Some of us have not used wikis, and thus do not feel comfortable using them."

Being convenient to everybody in the team implies a strong adoption of a technology tool, in the sense that everyone in the team already uses it, or is open and willing to learn to use it for the team. Our finding shows that Facebook has the strongest adoption among the respondents. $100 \%$ of the respondents said that they used Facebook in their team collaboration.

\subsubsection{Convenient to access and use}

Being convenient to everybody in the team appears to be necessary but not sufficient for a particular technology tool to be chosen by students for team use. All the students have an account in my courses, the University's learning management system. They have to access and use it regularly to download course materials, submit assignments, and see course-related announcements. However, none of the participants chose to use the my courses discussion forums in their team collaboration:

"My courses is not easy to use. It requires logging in, which takes long time."

"It is not an alternative that popped into our minds to use - Facebook is just much simpler and easier to use. We can also access Facebook from our smart phones so any time anywhere, which is not true for my courses." 
"My courses is slow and not easy to use. It is annoying because it disconnects me frequently. We all are on Facebook, always connected, so why bother with my courses?"

"Everyone has a smart phone and would most likely be on Facebook, but not on my courses."

Being convenient to access and use means a tool's ubiquity, ease of access, and ease of use.

\subsubsection{Convenient to collaborate with each other privately within the team}

Another factor that is identified as a factor impacting students' technology choice is convenient to collaborate with each other within the team. We analyzed the survey responses to "If used, where and how did you and your team use this tool for what purposes?" to identify a relationship between students' technology choice and types of collaborative interactions. The coding process revealed the two types of interactions that occur, as students collaborate to do the team project together with their team members: activity coordination and content co-creation, as illustrated in Fig. 2.

The activity coordination type of interactions is a type of interactions that occur as students attempt to coordinate activities required to do the team assignment together, with the evaluation criteria and deadlines in mind. These collaboration activities include diving up work, identifying and selecting, scheduling, sharing, discussing, confirming, and informing each other. The content co-creation type of interactions is a type of interactions that occur as students attempt to co-produce content in the form of a report or presentation slides, with the evaluation criteria and deadlines in mind. The collaboration activities revealed through the analysis include collecting, sharing, putting together ideas, discussing, organizing, working on documents simultaneously, updating, and tracking shared ideas.

\subsubsection{Convenient for activity coordination type of interactions}

Students used Facebook as a primary tool for the activity coordination type of interactions. They took advantage of Facebook's rich set of easy-to-use functionalities to facilitate interactions with their team members:

"We used Facebook to schedule meetings, to post a link to information to discuss relevancy, to communicate whenever we had problems or questions, and to give feedback."

"We are much more comfortable using Facebook to communicate. We get quick notifications from Facebook when someone posts like a change in the meeting location or the meeting time."

"Planning a meeting could be a hard task. All the members have a different schedules and priorities. Hence, we used Facebook groups to facilitate the communication among us, in order to ease the planning of meetings. It allowed everyone in the team to give his/her thoughts." 


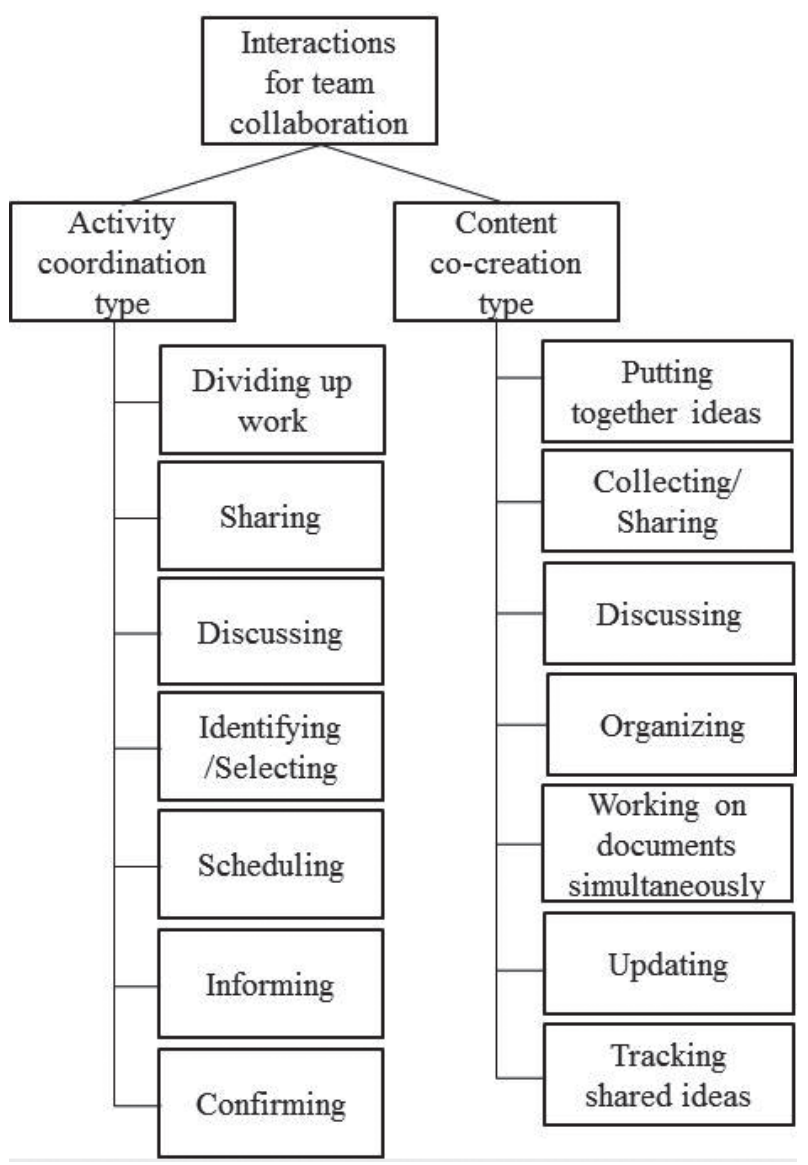

Fig. 2. Types of collaborative interactions that occur in team collaboration.

"Since everybody is on the Facebook, it is convenient to discuss and set meeting times and locations, and share links when we found something interesting to discuss."

"We used Facebook to schedule meetings, share ideas, talk about issues we were having, share what we were working on, and keep in contact."

"We used Facebook to schedule meetings, split parts, ask each other small questions while each of us worked on individual parts, as well as to post links to the versions of presentations and documents so that we can edit them all together." "Skype and Google Hangout are all good tools to use to interact. But, Facebook already did that for us so we didn't need redundant tools."

"Facebook makes everything simpler. Everybody is on it. Everything is in one place." 
"We used Facebook to schedule meetings, select topics, discuss feedback, confirm analysis and report details. If there is any change, I am notified real time."

The analysis reveals that millennial students can put boundaries in sharing. They limited the scope of sharing to the members within the team, by creating private groups within Facebook. They share project-related matters openly with their members, while keeping team communications and activities private to themselves within the team. Students have accounts with Twitter that is convenient to access and use with the affordances to support the activity coordination type of interactions. However none of the teams used Twitter, mainly due to Twitter's public nature:

"Twitter is not a good team communication tool since it is public. Besides, we wouldn't be able to write much."

"Twitter is not fast enough and too public to use to communicate with team mates. Much less effective than specific group posts on Facebook."

"Twitter is too public with lots of noise. In Facebook, we can keep team interactions to ourselves within my team. It is also convenient, because you don't have to befriend them in "group" function in order to do a group project for one semester. This means if there are certain conflicts within the group, you don't have to share personal information with them as friends. So it is cool."

"We all have a Facebook account, and setting up a private group in Facebook to communicate only with my team members is extremely easy and convenient. I admit it is not perfect, and can be distractive at times. But I can't stay distracted too long because I soon get notifications from my team members that I need to respond with my input."

In addition to Facebook, other tools such as Skype, Google Hangout, email, mobile phone texting offer affordance to facilitate the activity coordination type of interactions with each other within a team. And most of students are familiar with these tools - convenient to everyone in the team and convenient to access and use. Yet, they were not used as primary tools in team collaboration, because these tools offer limited functionalities for team-based collaborative interactions and thus are not as convenient as Facebook.

\subsubsection{Convenient for content co-creation type of interactions}

Students used Google Drive, Google Doc and Google Presentation for content co-creation type of interactions, as these tools provide the various sharing and content co-development features that students found convenient to collaborate with each other for content co-creation:

"Google Drive accepts large files, make one place where everyone will access and share the project files."

"Google Doc makes it much easier to collaborate without having to deal with multiple versions. We just post the link on Facebook. Not perfect, though, because it doesn't always format well when downloaded as a pdf." 
"Live real-time comment and edit system is super convenient."

"Very convenient, especially when doing a group project and everyone is working on it - easy to see who is working on what real time. It is particularly great under tight deadlines."

"Everyone has access to input. I can see teammates progress. It is one of the easiest ways to collaborate and make sure all team members are on the same page."

"We chose this tool so that we could all edit and collaborate on one document. We felt it was important to get the input of every member of the team."

"It is the best way to promote transparency in the group. Everyone can see what everyone is working on and can edit it any time. The real time feature allows us to see who is making edits, which is useful to know who is working at that moment. I know we all are doing our shares, contributing."

Students chose collaboration technologies convenient to collaborate with other, so as to work on documents simultaneously with the transparency that everybody in the team can see who is contributing on what.

\subsubsection{Team-level technology choice for use in team collaboration}

Not all teams chose the same set of technologies for use in their collaborative learning activities. 50\% of the teams used Facebook, Google Doc, Google Presentation, and Google Drive as primary tools in their team collaboration. These teams, hereafter referred to as collaboration tech-literate teams, used Facebook as a primary tool for the activity coordination type of interactions, while using Google Doc, Google Presentation, and Google Drive as primary tools for the content co-creation type of interactions. Emails and texting were not used as primary communication tools in these teams. The usage of emails and texting was limited mainly to the cases when a team member was not responding to Facebook notifications in a timely manner or when they have to communicate with people external to the team such as managers of the company that they were collecting data from for the project.

$29 \%$ of the teams used Facebook and Google Doc as their primary tools in their team collaboration. These teams, hereafter referred to as limited collaboration techliterate team, used Facebook for the activity coordination type of interactions, while using Google Doc for report content co-creation and traditional presentation tool (Microsoft Office Presentation) for co-creation of presentation slides. The traditional presentation tool was used because some of the team members were not familiar with Google Presentation, and thus was not convenient to everyone in the team. Emails and texting were not primary communication tools used by these teams, similar to the collaboration tech-literate teams.

$21 \%$ of the teams used Facebook, emails, and mobile phone texting as the main tools for project collaboration. These teams, hereafter referred to as collaboration tech-challenged teams, used the Facebook, emails, and mobile texting for the activity coordination type of interactions, while traditional word processing and presentation tools (Microsoft Office Word and Microsoft Office Presentation) for content 
co-development. The collaboration tools that offer the social affordances to facilitate the content co-creation type of interactions (such as Google Doc and Google Presentation) were not selected by these teams because some of their team members were not familiar with the tools, and thus were not convenient to everyone in the team.

The team-level analysis to explain the difference in technology choice reveals that being convenient to everybody in the team appears to be a key factor in students' making a trade-off decision on which technology tools to use in their collaborative learning activities. Students in the collaboration tech-literate teams were all familiar with, or open and willing to learn to use, the tools that they selected. On the other hand, some of students in the limited collaboration tech-literate team and collaboration tech-challenged teams were not familiar with a certain collaboration technology tool such as Google Doc and Google Presentation. This led to the decision not to use such a tool in their team collaboration, despite its convenience to collaborate with each other for content co-creation together, because it was not convenient to everybody in the team.

\subsection{Impact of technology choice on students' collaborative learning experience and performance}

The question was asked to students to assess their collaborative learning experience, as they worked together to do the project with the use of the technologies chosen by them. To the question of "Overall, would you say that the technology tools that your team used to do this team project helped you to interact better with your team members and learn from each other, thus helping you to have positive, meaningful learning experience?" the survey participants answered in one of the five levels - strongly agree, agree, neither agree nor disagree, disagree, strongly disagree.

All of the survey participants responded with the answer of either agree or strongly agree $-65 \%$ of students (33 out of 51 ) responding with strongly agree, while $35 \%$ agreeing. Figure 3 shows a distribution between a team's technology choice and the impact of the technology choice on students' collaborative learning experiences. It indicates that a particular set of technology choices could impact students' collaborative learning experience. The majority of the students who responded with "strongly agree" were those in the collaboration tech-literate teams. This finding suggests that while the use of collaborate technologies in their team project does not guarantee a strongly positive learning experience to all students, it is more likely to result in students with strongly positive learning experience than otherwise.

As illustrated in Fig. 4, a moderately strong positive correlation with statistical significance ( $r=0.425, p<0.01$ ) is found between a student's perception on the impact of the use of the technologies chosen by them on his/her collaborative learning experience and collaborative learning performance, measured at a team level according to the criteria specified in the Course Design section, 


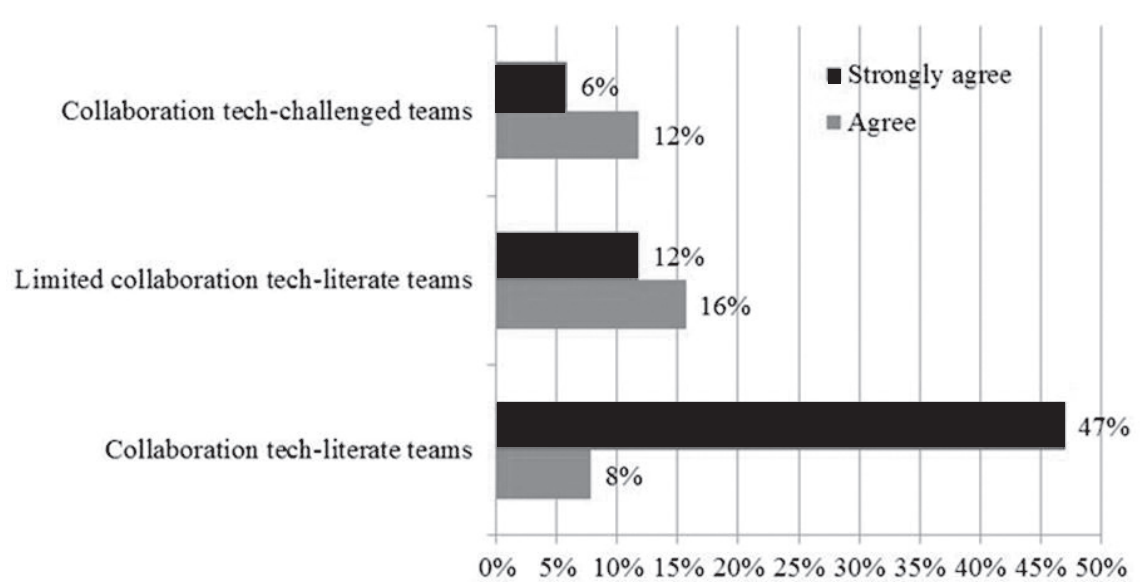

Fig. 3. A distribution between a team's technology choice and the impact of the technology choice on students' collaborative learning experiences.

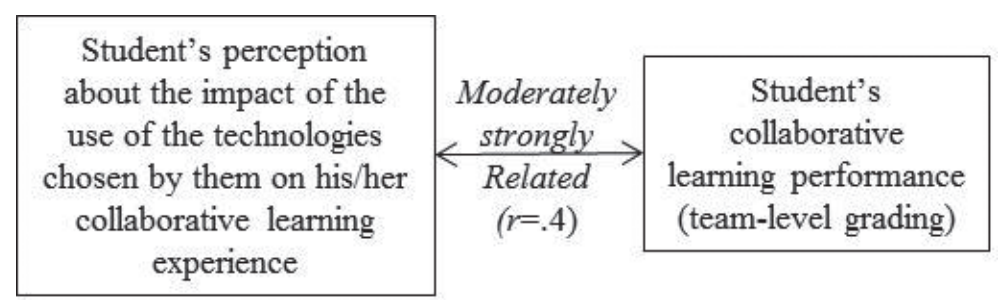

Fig. 4. Correlation (r-value): student's perception on the impact of the use of the technologies chosen by them on collaborative learning experience and their collaborative learning performance.

\section{Discussion and conclusion}

This study sought to examine what drives millennial students' technology choice and how their technology choice may impact their collaborative learning experience and performance. A team-based collaborative learning assignment was designed as a part of a pedagogic strategy in a university-level, on-campus course. The successful completion of this team assignment requires that students collaborate in teams to problem solve together by applying the concepts and frameworks taught in class to a real-world situation, while using critical soft skills in connection with the learning of the domain knowledge. The millennial students in the study cohort, familiar with a variety of social media and collaboration technologies that afford collaborative potential at varying degrees, did not automatically make extensive use of all these familiar technologies. Instead, they chose some of them for use in their teambased collaborative learning activities - collectively among themselves, but independently and autonomously without requiring a teacher's intervention. The finding 
of this study supports the conclusion by Lee and McLoughlin [39] that students' adoption of a particular technology tool is ultimately determined by the "views and perceptions of the users (learners)." Our analysis reveals a primary decision factor explaining students' pick-and-choose behaviors of selecting the particular social media and collaboration technology tools for use in learning together. The common theme that emerges as a principal decision factor is convenience, i.e., a quality of being easy, useful, or suitable to proceed with something without difficulty. Three salient types of convenience that play a role in students' technology choice for use in their collaborative learning activities are identified - convenient to everybody in the team, convenient to access and use, and convenient to collaborate with each other privately within the team. The team-based collaboration to achieve the project learning outcomes, with the evaluation criteria and deadlines in mind, influenced students' choice of technology to support the two types of collaborative interactions - the activity coordination type of interactions and the content co-creation type of interactions. This study provides evidence on the positive impact of the use of the technologies chosen by millennial students on their collaborative learning experience, which also shows a moderately strong positive correlation with their collaborative learning performance. The analysis provides an informed basis to propose a student-engaged technology-choice-and-impact framework for technology-assisted, team-based collaborative learning, as illustrated in Fig. 5 (hereafter, referred to as STCI framework).

The STCI framework conceptualizes relationships among various key components in technology-assisted, team-based collaborative learning - team assignment objectives, evaluation and assessment schemes, students' primary decision factors impacting their technology choice from a pool of familiar technologies, the technologies chosen for use in team collaboration, team collaboration using the technologies chosen, collaborative learning deliverables, and collaborative learning experience and performance.

Active participation of students in technology choice for use in their collaborative learning activities is made explicit in the STCI framework. Educators can tailor the SCTI framework to design team-based collaborative learning programs that engage tech-savvy millennial students in the decision making of technologies to use in their learning activities, and monitor the impact to improve collaborative learning experience and performance. In addition, the framework can be used at an institution level in higher education to keep track of not only technologies familiar to students but also primary decision factors impacting their technology choice for use in learning activities. Such information can help higher education institutions to design institution-level education technology strategies that reflect students' changing needs.

The STCI framework has also implications to the education technology provider community and the education research community. The education technology provider community can use the study findings and the STCI framework to guide the design of education technologies with learners in mind, in such a way that they can 


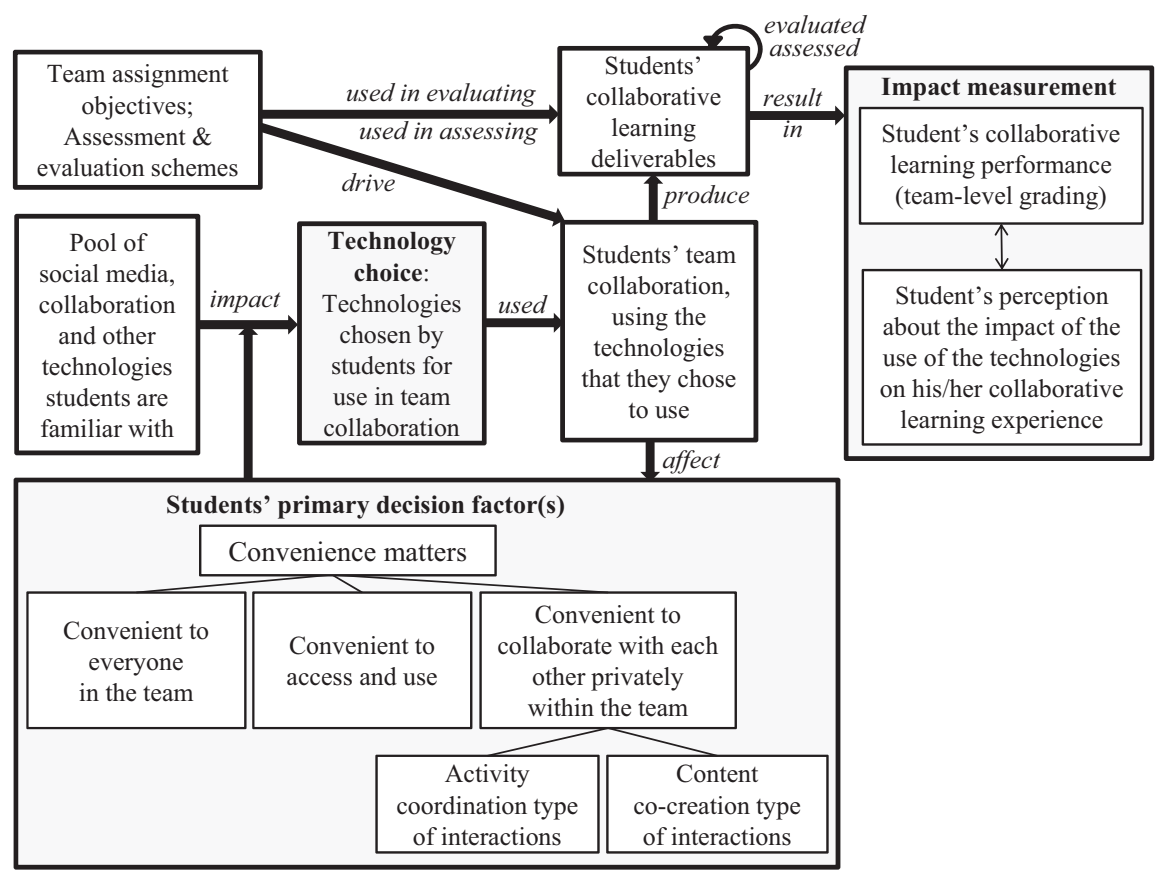

Fig. 5. Student-engaged technology-choice-and-impact (STCI) framework for technology-assisted, teambased collaborative learning.

be conveniently integrated to support millennial students' learning activities. Techsavvy, socially connected millennial students can assess how best to use a particular technology tool to meet their needs in performing learning activities. When there are multiple competing tools that offer same or similar affordances, they avoid redundancy by choosing one that they collectively decide is most convenient to them. Thus, LMS providers will need to define the role of LMS to be conveniently integrated and remain relevant in students' learning activities.

The STCI framework allows to identify the future research needs to further investigate the role of teachers in technology choice, the integration of knowledge management, and the impact of an assessment and evaluation approach on students' technology choice and collaborative learning performance. There seems a general consensus that a different environment has emerged for millennial students with pervasive use of social and collaboration technologies in their daily lives. This change alone does not guarantee, however, that learners reliably benefit from the social affordances that these tools offer. The findings of this study suggest that a particular technology choice made by students for use in their collaborative learning activities could impact the degree of positive collaborative learning experience. More students in the teams that used collaboration technologies strongly agreed that the use of the technologies chosen by them positively impacted their collaborative learning 
experience (Fig. 3). The key reason why some teams decided not to use collaboration technology tools was because some of their team members were not familiar with these tools. In other words, some students in these teams were not as tool and emerging technology literate as others. Thus, the further research should explore the mechanisms and impact of incorporating the role of teachers in students' technology choice into the STCI framework, in order to minimize learning disparity due to students' lack of tool literacy and emerging technology literacy defined by Shapiro and Hughes [57].

The analysis on being convenient to collaborate with each other privately within the team reveals the two types of collaborative interactions that impact students' technology choice - the activity coordination type of interactions and the content co-creation type of interactions. These two types of collaborative interactions share many of the knowledge management activities identified in O'Dell's knowledge management framework (1996) - i.e., identify, collect, adapt, organize, apply, share, and create. The possibility of using social media in knowledge management in higher education was raised to be properly addressed [9]. Further research should explore the mechanics to incorporate knowledge management into the STCI framework along students' collaborative learning cycle and assess its impact on their collaborative learning experience and performance.

The findings of this study are based on the formative assessment and evaluation scheme described in the Course Design section. Future research should include considerable observation and testing to understand how change in assessment and evaluation approaches would impact millennial students' technology choice, their collaborative learning experience and performance in higher education. Such understanding can help guide the design of assessment and evaluation for team-based collaborative learning that leads to meaningful improvements in student engagement and learning outcomes.

The higher education and technology field is rich with volumes of work to understand the ways in which learning management systems, social media, and other forms of ICTs can be approached for higher education. Despite this, we have argued that we have a limited understanding of millennial students' choice of technologies for their collaborative learning activities and its impact on learning experience and performance. This research shows that millennial students in higher education can choose, from a wide pool of technologies available to them, the technologies that make sense for their learning tasks. Convenience emerges as a primary decision factor impacting students' technology of choice for use in their collaborative learning interactions. This paper confirms the importance of studying pedagogic strategies that engage students in technology choice and the impact on students' collaborative learning experience and performance. We hope this research will provide further impetus for continuing the journey of advancing our understanding of student engagement in harnessing ever-changing technological capabilities to create a new reality of collaborative learning in higher education. 


\section{Limitation}

This study was conducted with an on-campus, IT management course designed for final-year students in a Canadian university. Thus, more research should be implemented using various course subjects, different learning environments, different school settings, and ages, for more extensive quantitative data collection to compare and test the framework.

\section{References}

[1] P.C. Abrami, R. Bernard, A. Wade, R.F. Schmid, E. Borokhovski, R. Tamin and A. Peretiatkowicz, A review of e-learning in Canada: A rough sketch of the evidence, gaps and promising directions, Canadian Journal of Learning and Technology/La revue canadienne de l'apprentissageet de la technologie 32(3) (2008).

[2] H. Ajjan and R. Hartshorne, Investigating faculty decisions to adopt Web 2.0 technologies: Theory and empirical tests, The Internet and Higher Education 11(2) (2008), 71-80.

[3] T. Anderson and H. Kanuka, Using constructivism in technology-mediated learning: Constructing order out of the chaos in the literature, 1999.

[4] J. Andrews and H. Higson, Graduate employability, 'soft skills' versus 'hard'business knowledge: A European study, Higher Education in Europe 33(4) (2008), 411-422.

[5] A.W. Astin, Assessment for excellence: The philosophy and practice of assessment and evaluation in higher education. Rowman\& Littlefield Publishers, 2012.

[6] P. Avgeriou, A. Papasalouros, S. Retalis and M. Skordalakis, Towards a pattern language for learning management systems, Educational Technology \& Society 6(2) (2003), 11-24.

[7] A.W. Bates and G. Poole, Effective Teaching with Technology in Higher Education: Foundations for Success. Jossey-Bass, An Imprint of Wiley. 10475 Crosspoint Blvd, Indianapolis, IN 46256, 2003.

[8] A.T. Bates and A. Sangrà, Managing technology in higher education: Strategies for transforming teaching and learning. John Wiley \& Sons, 2011.

[9] V. Benson, S. Morgan and H. Tennakoon, A framework for knowledge management in higher education using social networking, International Journal of Knowledge Society Research (IJKSR) 3(2) (2012), 44-54.

[10] M. Blankenship, How social media can and should impact higher education, Education Digest 76(7) (2011), 39-42.

[11] B. Cavas, P. Cavas, B. Karaoglan and T. Kisla, A Study on Science Teachers' Attitudes Toward Information and Communications Technologies in Education, Online Submission 8(2) (2009).

[12] K. Charmaz, Grounded theory in the 21st century, in: Handbook of Qualitative Research. N.K. Denzin and Y.S. Lincoln, eds, CA: Sage, 2005.

[13] B. Chen and T. Bryer, Investigating instructional strategies for using social media in formal and informal learning, The International Review of Research in Open and Distance Learning 13(1) (2012), 87-104.

[14] C.M. Christensen and H.J. Eyring, The innovative university: Changing the DNA of higher education from the inside out. John Wiley \& Sons, 2011.

[15] M.A. Conde, F. García, M.J. Rodríguez-Conde, M. Alier and A. García-Holgado, Perceived openness of Learning Management Systems by students and teachers in education and technology courses, Computers in Human Behavior 31 (2014), 517-526.

[16] D. Conrad and R. Newberry, 24 Business communication skills: Attitudes of human resource managers versus business educators, American Communication Journal 13(1) (2011), 4-23.

[17] N. Dabbagh and A. Kitsantas, Personal Learning Environments, social media, and self-regulated learning: A natural formula for connecting formal and informal learning, The Internet and Higher Education 15(1) (2012), 3-8. 
[18] M. Drent and M. Meelissen, Which factors obstruct or stimulate teacher educators to use ICT innovatively? Computers \& Education 51(1) (2008), 187-199.

[19] P. Dillenbourg, What do you mean by collaborative learning? Collaborative-learning: Cognitive and Computational Approaches, 1999, 1-19.

[20] H. Eijkman, Dancing with postmodernity: Web 2.0 as a new epistemic learning space. In Web, 2010, pp. 343-364.

[21] B.G. Glaser and A.L. Strauss, The discovery of grounded theory: Strategies for qualitative research. Transaction Publishers, 2009.

[22] G. Grosseck, To use or not to use web 2.0 in higher education? Procedia-Social and Behavioral Sciences 1(1) (2009), 478-482.

[23] G. Heiberger and R. Harper, Have you FacebookedAstin lately? Using technology to increase student involvement, New Directions for Student Services 2008(124) (2008), 19-35.

[24] P.C. Honebein, Seven goals for the design of constructivist learning environments, Constructivist learning environments: Case studies in instructional design, 1996, 11-24.

[25] L. Johnson, S. Adams, M. Cummins, V. Estrada, A. Freeman and H. Ludgate, The NMC horizon report: 2013 higher education edition, 2013.

[26] R. Junco, C.M. Elavsky and G. Heiberger, Putting twitter to the test: Assessing outcomes for student collaboration, engagement and success, British Journal of Educational Technology 44(2) (2013), 273-287.

[27] R. Junco, Too much face and not enough books: The relationship between multiple indices of Facebook use and academic performance, Computers in Human Behavior 28(1) (2012), 187-198.

[28] R. Junco, G. Heiberger and E. Loken, The effect of Twitter on college student engagement and grades, Journal of Computer Assisted Learning 27(2) (2011), 119-132.

[29] A.M. Kaplan and M. Haenlein, Users of the world, unite! The challenges and opportunities of Social Media, Business Horizons 53(1) (2010), 59-68.

[30] J.E. Klobas and T.J. McGill, The role of involvement in learning management system success, Journal of Computing in Higher Education 22(2) (2010), 114-134.

[31] S. Kopyc, Enhancing teaching with technology: Are we there yet, Innovate Journal of Online Education 3(2) (2006).

[32] G.M. Kundi and A. Nawaz, From objectivism to social constructivism: The impacts of information and communication technologies (ICTs) on higher education, Journal of Science and Technology Education Research 1(2) (2010), 30-36.

[33] M.J. Lee and C. McLoughlin, Harnessing the affordances of Web 2.0 and social software tools: Can we finally make "student-centered" learning a reality? In World conference on educational multimedia, hypermedia and telecommunications (Vol. 2008, No. 1, pp. 3825-3834), 2008.

[34] J.D. Lewis, Partnerships for profit: Structuring and managing strategic alliances. Simon and Schuster, 2002.

[35] S. Lonn and S.D. Teasley, Saving time or innovating practice: Investigating perceptions and uses of Learning Management Systems, Computers \& Education 53(3) (2009), 686-694.

[36] J. Malcolm, P. Hodkinson and H. Colley, The interrelationships between informal and formal learning, Journal of Workplace Learning 15(7/8) (2003), 313-318.

[37] J. Mao, Social media for learning: A mixed methods study on high school students' technology affordances and perspectives, Computers in Human Behavior 33 (2014), 213-223.

[38] T.M. McCarthy and S.L. Golicic, Implementing collaborative forecasting to improve supply chain performance, International Journal of Physical Distribution \& Logistics Management 32(6) (2002), 431-454.

[39] C. McLoughlin and M.J. Lee, Social software and participatory learning: Pedagogical choices with technology affordances in the Web 2.0 era. In ICT: Providing choices for learners and learning. Proceedings ascilite Singapore 2007, 2007, pp. 664-675.

[40] M. Moran, J. Seaman and H. Tinti-Kane, Teaching, Learning, and Sharing: How Today's Higher Education Faculty Use Social Media, Babson Survey Research Group, 2011.

[41] N.J. Morel, Setting the Stage for Collaboration: An Essential Skill for Professional Growth, International Journal for Professional Educators 36 (2014), 9. 
[42] S. Mumtaz, Factors affecting teachers' use of information and communications technology: A review of the literature, Journal of Information Technology for Teacher Education 9(3) (2000), 319342 .

[43] W. Ng, H. Nicholas, S. Loke and T. Torabi, Designing effective pedagogical systems for teaching and learning with mobile and ubiquitous devices, Multiplatform e-learning systems and technologies: mobile devices for ubiquitous ICT-based education, 2010, 42-56.

[44] M.L. Niess, Investigating TPACK: Knowledge growth in teaching with technology, Journal of Educational Computing Research 44(3) (2011), 299-317.

[45] C. O'Dell, (1996, December). A current review of knowledge management best practice. In conference on knowledge management and the transfer of best practices, Business Intelligence, London.

[46] M. Oliver, Technological determinism in educational technology research: Some alternative ways of thinking about the relationship between learning and technology, Journal of Computer Assisted Learning 27(5) (2011), 373-384.

[47] T. O'Reilly, What is Web 2.0. 2005. See http://www.oreillynet.com/pub/a/oreilly/tim/news/2005/09 130/what-is-web-20.html.

[48] C.A. Palomba and T.W. Banta, Assessment Essentials: Planning, Implementing, and Improving Assessment in Higher Education. Higher and Adult Education Series.Jossey-Bass, Inc., Publishers, 350 Sansome Street, San Francisco, CA 94104, 1999.

[49] H. Parker, Interfirm collaboration and the new product development process, Industrial Management \& Data Systems 100(6) (2000), 255-260.

[50] M. Prensky, Digital natives, digital immigrants. Cross Currents: Cultures, Communities, Technologies, 2013.

[51] C. Redecker, K. Ala-Mutka and Y. Punie, Learning 2.0-The impact of social media on learning in Europe. Policy brief.JRC Scientific and Technical Report. EUR JRC56958 EN, available from: http://bit.ly/cljlpq [Accessed 6th February 2011], 2010.

[52] M.D. Roblyer, M. McDaniel, M. Webb, J. Herman and J.V. Witty, Findings on Facebook in higher education: A comparison of college faculty and student uses and perceptions of social networking sites, The Internet and Higher Education 13(3) (2010), 134-140.

[53] J.E. Rodriguez, Social media use in higher education: Key areas to consider for educators, 2011.

[54] J. Roschelle and S. Teasley, The construction of shared knowledge in collaborative problem solving, in: Computer-Supported Collaborative Learning, C. O’Malley, ed., Berlin, Germany: Springer Verlag, 1995, pp. 69-197.

[55] J.P. Rossing, W.M. Miller, A.K. Cecil and S.E. Stamper, iLearning: The Future of Higher Education? Student Perceptions on Learning with Mobile Tablets, Journal of the Scholarship of Teaching and Learning 12(2) (2012), 1-26

[56] B. Rubin, R. Fernandes, M.D. Avgerinou and J. Moore, The effect of learning management systems on student and faculty outcomes, The Internet and Higher Education 13(1) (2010), 82-83.

[57] J.J. Shapiro and S.K. Hughes, Information literacy as a liberal art? Educom Review 31 (1996), 31-35.

[58] B. Sasseville, Integrating information and communication technology in the classroom: A comparative discourse analysis, Canadian Journal of Learning and Technology 30 (2004), 5-28.

[59] N. Selwyn, Social media in higher education. The Europa world of learning, 2012.

[60] P.M. Senge, The Fifth Discpline. Doubleday, 1990.

[61] J. Stark, Product lifecycle management Springer London, 2011, pp. 1-16.

[62] M.J. Sutton and A. Hazeri, Using the Wiki as an Experiential Learning Tool to Engage Students in Undergraduate and Graduate University Courses, Increasing Student Engagement and Retention Using Online Learning Activities: Wikis, Blogs and Webquests, Vol. 6. Emerald Group Publishing: UK, 2012.

[63] R. Sweeney, Millennial behaviors and demographics, Newark: New Jersey Institute of Technology. Accessed on 12(3) (2006), 10.

[64] P.A. Tess, The role of social media in higher education classes (real and virtual) - A literature review, Computers in Human Behavior 29(5) (2013), A60-A68.

[65] T. Teo and J. Noyes, An assessment of the influence of perceived enjoyment and attitude on the 
intention to use technology among pre-service teachers: A structural equation modeling approach, Computers \& Education 57(2) (2011), 1645-1653.

[66] UNESCO. World conference on higher education: The new dynamics of higher education and research for societal change and development. UNESCO, Paris (2009).

[67] J. Voogt, P. Fisser, N. Pareja Roblin, J. Tondeur and J. van Braak, Technological pedagogical content knowledge - a review of the literature, Journal of Computer Assisted Learning 29(2) (2013), $109-121$.

[68] L. Yuan, S. Powell and J. CETIS, MOOCs and open education: Implications for higher education. Cetis White Paper, 2013.

[69] J. Webster and P. Hackley, Teaching effectiveness in technology-mediated distance learning, Academy of Management Journal 40(6) (1997), 1282-1309. 